\title{
Earthworm diversity and abundance in different habitats at Satyajit Ray Film and Television Institute, Kolkata
}

\author{
Rinku Goswami* \\ Zoological Survey of India, M - Block, New Alipore, Kolkata - 700053, India; rinku-zsi@yahoo.co.in
}

\begin{abstract}
An ecological survey of earthworms was conducted at Satyajit Ray Film and Television Institute (SRFTI), Kolkata for the period of one year during August 2016-July 2017. The aim of the present study is to determine the abundance and diversity of earthworms under different land use pattern. Earthworms were collected from three different sites in SRFTI based on environment niches like grasslands, residential areas, bank of the water bodies etc., by hand sorting method. Total 8 species of earthworms were identified from 537 specimens collected and abundance plot of earthworm species were arranged by rank. The highest relative abundance of Metaphire posthuma found at the bank of water bodies, Metaphire peguana and Metaphire posthuma in residential areas and Metaphire peguana in grassland habitat, whereas the lowest relative abundance of Metaphire houlleti found in all the habitats. The highest number of species and genera were recorded in the residential areas, the least in grassland habitat. The diversity value also was highest in the residential areas with the lowest in grassland habitat. Though the highest evenness value found in the bank of the water bodies. The Dominance (d) Index value was the highest in grassland habitat with the lowest in the residential areas. The highest similarity was observed between bank of water bodies and grassland habitat.
\end{abstract}

Keywords: Abundance, Diversity, Earthworm, SRFTI

\section{Introduction}

Earthworms have over 200 years of scientific attention (Satchell, 1983). They are the larger members of the Oligochaeta, Phylum Annelida. The effects of earthworms on ecosystems are usually considered positive because of their role in aerating and enriching soils (Coleman et al., 2004; Baskin, 2005). In tropics, studies on diversity, ecology, and role of earthworms have been carried out in Savanna (Lavelle, 1974), pasture (Dash and Patra, 1977), rain forests (Fragoso and Lavelle 1992) and agricultural lands (Sathianarayanan and Khan, 2006).

The study area SRFTI (Satyajit Ray Film and Television Institute) named after the legendary film maestro Satyajit Ray. This is an academic institution under the Ministry of Information and Broadcasting, Government of India situated at Kolkata, West Bengal. The campus spread over 40 acres, which houses the academic and administrative buildings, one guest house, student hostels and staff quarters. In addition, there are grasslands with children playground and two water bodies. The larger of them has two small islands within it. About one third of the area of the campus is still undeveloped, mostly swamps and fields with shrubs.

Earthworms were collected from three different sites in SRFTI based on environmental niches like grasslands, residential areas, bank of the water bodies etc. The study assessed the abundance and diversity of species composition of earthworm communities across three varied ecosystems in SRFTI campus.

\section{Material and Methods}

Earthworm's quantitative sampling was carried out by a sampling grid $(20 \mathrm{~m} \times 20 \mathrm{~m})$. The grid was marked at each site, containing 16 units of $5 \mathrm{~m} \times 5 \mathrm{~m}$, which were further divided into subunits of $1 \mathrm{~m}^{2}$. These $1 \mathrm{~m}^{2}$ subunits were selected randomly and no subunit was

\footnotetext{
* Author for correspondence
} 
sampled twice. During each sampling time, for each study site three widely separated subunits were randomly selected for sampling. Earthworms were collected by conventional digging $(25 \mathrm{~cm} \times 25 \mathrm{~cm} \times 30 \mathrm{~cm})$ and hand sorting method (Anderson and Ingram, 1993) from each quadrat. Earthworms were counted and narcotized by dropping them in $70 \%$ ethyl alcohol. They are removed from alcohol after their movement stopped. Then worms were transferred to $10 \%$ formalin for fixation and identification. Labels with site name, plot number, date were affixed to each vial.

Ecological indices were calculated by ShannonWiener diversity index (Ludwig and Reynolds, 1988) using the formula, $\mathrm{H}^{\prime}=-\sum \mathrm{p}_{\mathrm{i}} \ln \mathrm{p}_{\mathrm{i}}$, where $\mathrm{p}_{\mathrm{i}}$ is the relative abundance of the species $\left(p_{i}=n_{i} / N ; n_{i}\right.$ is the number of individual species, $\mathrm{N}$ is the total number of individuals). Simpson's index using formula, $\mathrm{D}=\sum \mathrm{n}_{\mathrm{i}}\left(\mathrm{n}_{\mathrm{i}}-1\right) / \mathrm{N}(\mathrm{N}-1)$ where total number of species of all species is $\mathrm{N}$ and total number of individuals of a particular species is $\mathrm{n}$. For better logical justification, inverse Simpson's diversity index (1/D) is used. Species dominance index, Species richness index, Species evenness and Cluster analysis index were also calculated with the help of Biodiversity professional, version 2 software.

\section{Results of Abundance}

The study revealed 537 specimens of earthworm collected during the period August 2016-July 2017. Sampling were done on pre monsoon, monsoon and post monsoon. The presence of 8 species of earthworms under 6 genera and 3 families were recorded from three sites of SRFTI campus. Abundance is estimated from abundance plot of the species which are arranged by rank. Table 1 shows this abundance plot of species which depicts that the highest abundance is found in residential areas (220), followed by grassland habitat (174) and the lowest abundance in the bank of water bodies (143). The highest relative abundance of earthworm species is found in Metaphire posthuma (25\%) and the least in Metaphire houlleti (15\%) at the bank of water bodies (Figure 1). The highest relative abundance of Metaphire peguana and Metaphire posthuma (19\%) with the lowest Metaphire houlleti (10\%) was recorded in residential areas (Figure 2). The highest relative abundance values of Metaphire peguana (51\%) with the lowest Metaphire houlleti and Drawida nepalensis (13\%) was recorded in grassland habitat (Figure 3).

\section{Abundance}

Table 1. Abundance plot of earthworm species found in SRFTI are arranged by rank

\begin{tabular}{|l|c|l|c|l|c|}
\hline Bank of waterbodies & $\begin{array}{c}\text { Bank of } \\
\text { waterbodies }\end{array}$ & Residential area & $\begin{array}{c}\text { Residential } \\
\text { area }\end{array}$ & Grassland \\
\hline Metaphire posthuma & 35 & Metaphire peguana & 42 & Metaphire peguana & 88 \\
\hline Metaphire peguana & 33 & Metaphire posthuma & 42 & Metaphire posthuma & 41 \\
\hline Eutyphoeus incommodus & 29 & Lampito mauritii & 36 & Drawida nepalensis & 23 \\
\hline Drawida nepalensis & 24 & Amynthas alexandri & 27 & Metaphire houlleti & 22 \\
\hline Metaphire houlleti & 22 & Drawida nepalensis & 27 & Amynthas alexandri & 0 \\
\hline Amynthas alexandri & 0 & Perionyx excavatus & 25 & Lampito mauritii & 0 \\
\hline Lampito mauritii & 0 & Metaphire houlleti & 21 & Perionyx excavatus & 0 \\
\hline Total & 143 & & 220 & & 174 \\
\hline
\end{tabular}




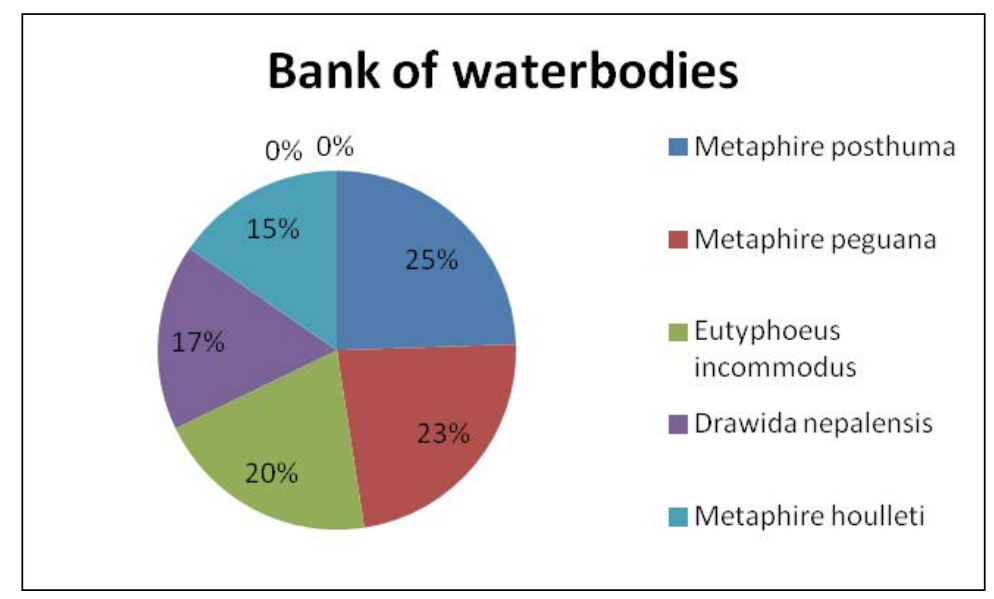

Figure 1. Abundance of earthworm species in bank of water bodies.

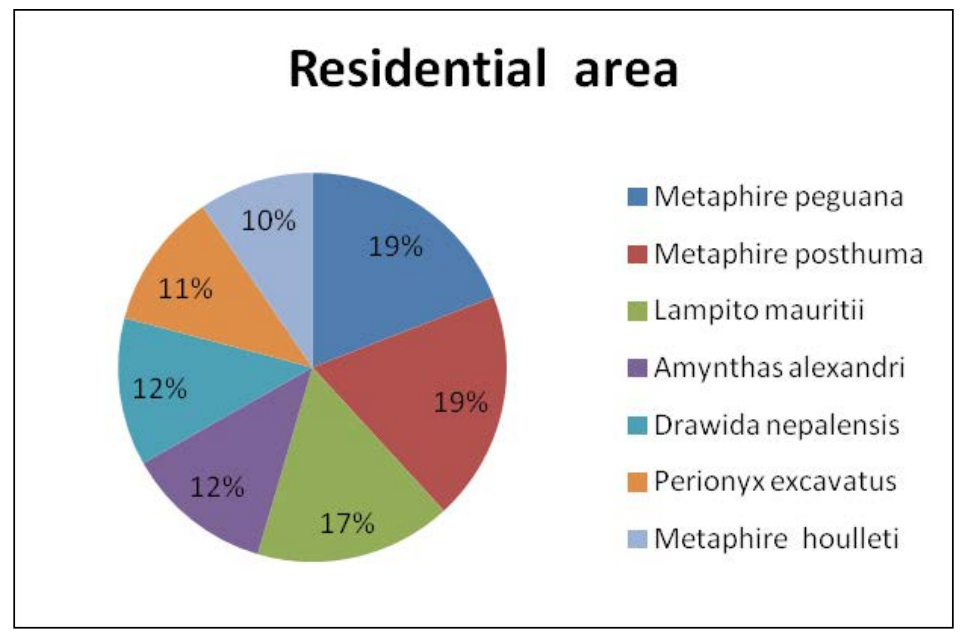

Figure 2. Abundance of earthworm species in residential areas.

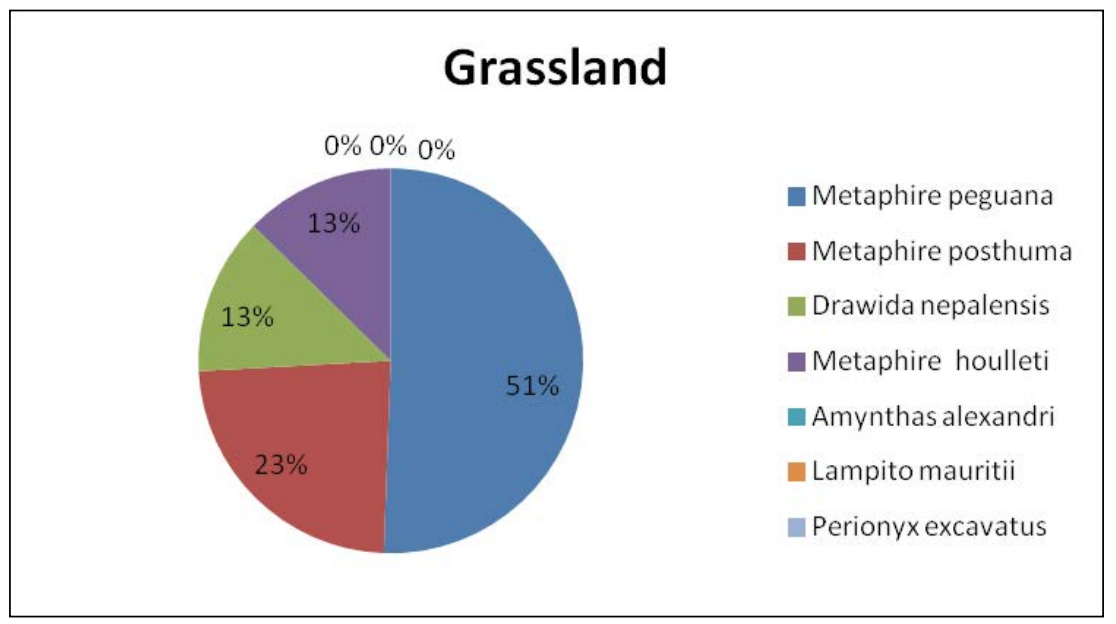

Figure 3. Abundance of earthworm species in grassland habitat 


\section{Diversity}

Table 2. Total number of species found in three different habitats in SRFTI campus

\begin{tabular}{|l|c|c|c|}
\hline Name of earthworm species & Bank of waterbodies & Residential area & Grassland \\
\hline Amynthas alexandri & 0 & 27 & 0 \\
\hline Lampito mauritii & 0 & 36 & 0 \\
\hline Metaphire houlleti & 22 & 21 & 22 \\
\hline Metaphire peguana & 33 & 42 & 88 \\
\hline Metaphire posthuma & 35 & 25 & 0 \\
\hline Perionyx excavatus & 0 & 27 & 23 \\
\hline Drawida nepalensis & 24 & 0 & 0 \\
\hline Eutyphoeus incommodus & 29 & & 21 \\
\hline
\end{tabular}

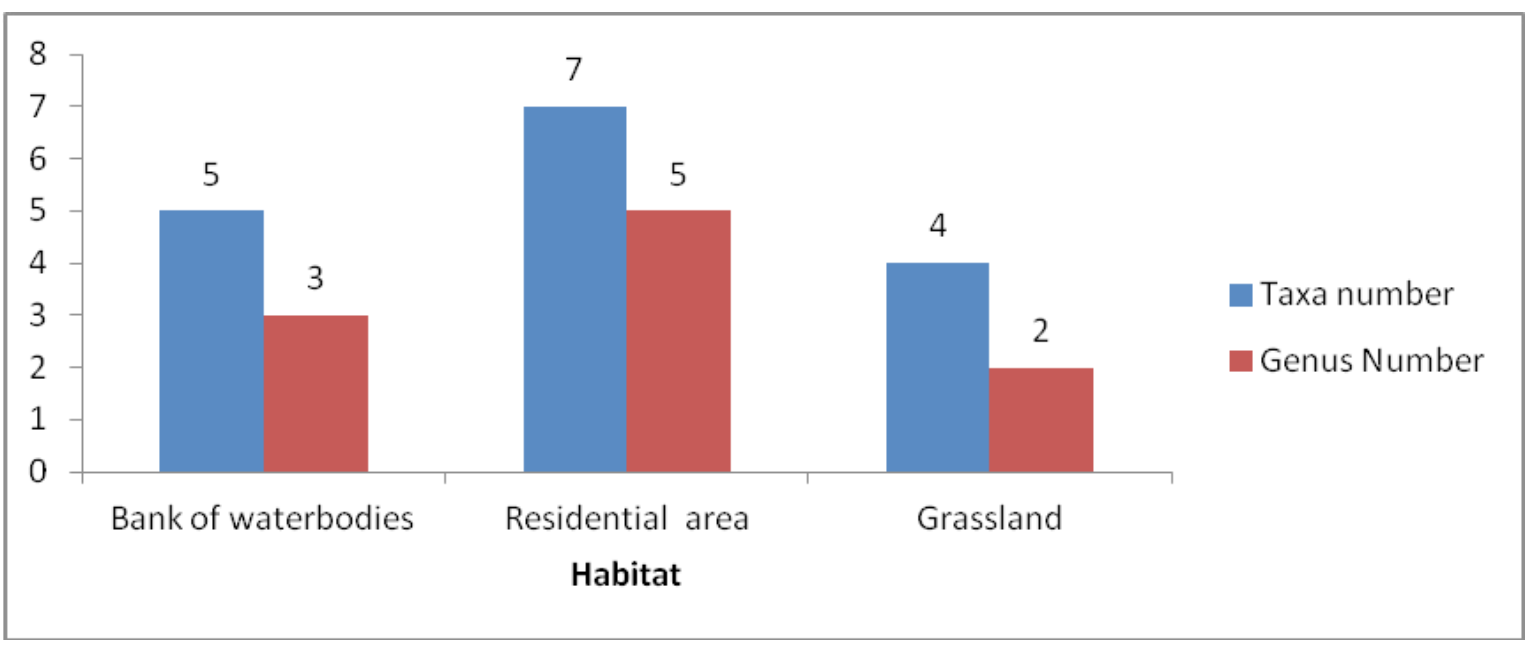

Figure 4. Number of earthworm species and genera in different habitats.

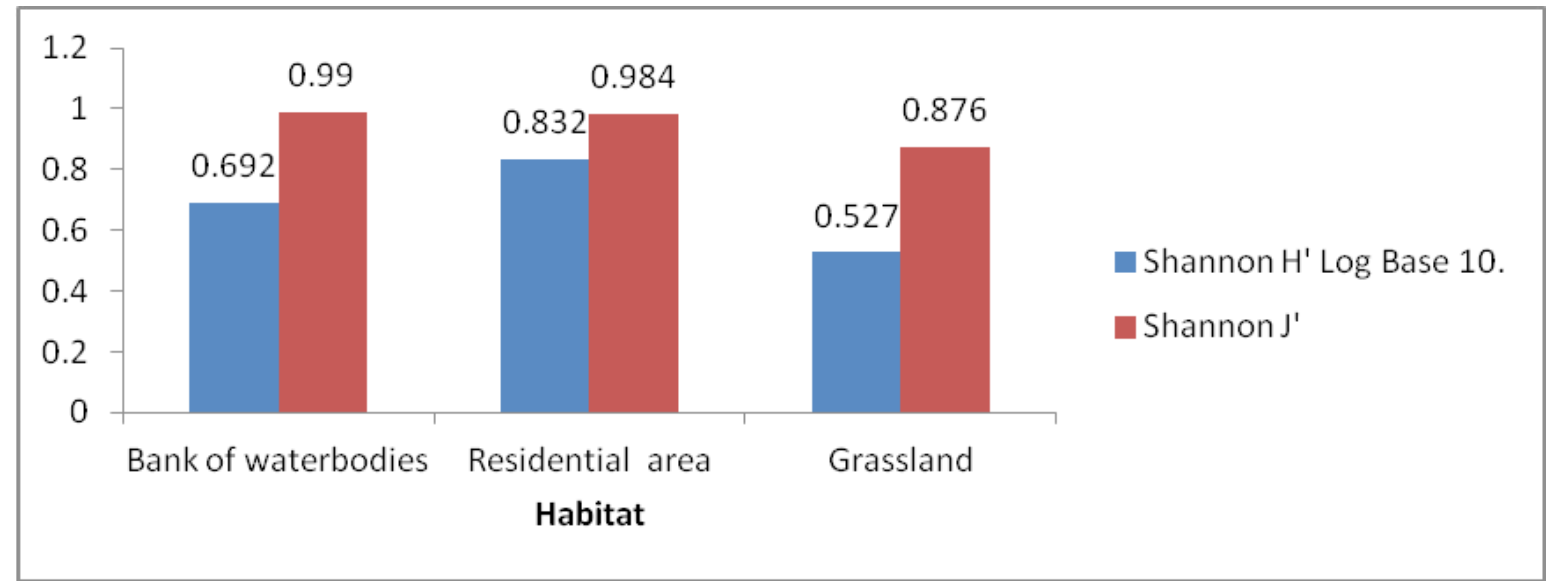

Figure 5. Shannon-Wiener Diversity Index (Shannon H' Log Base 10) and Evenness Index (Shannon J') in different habitats. 


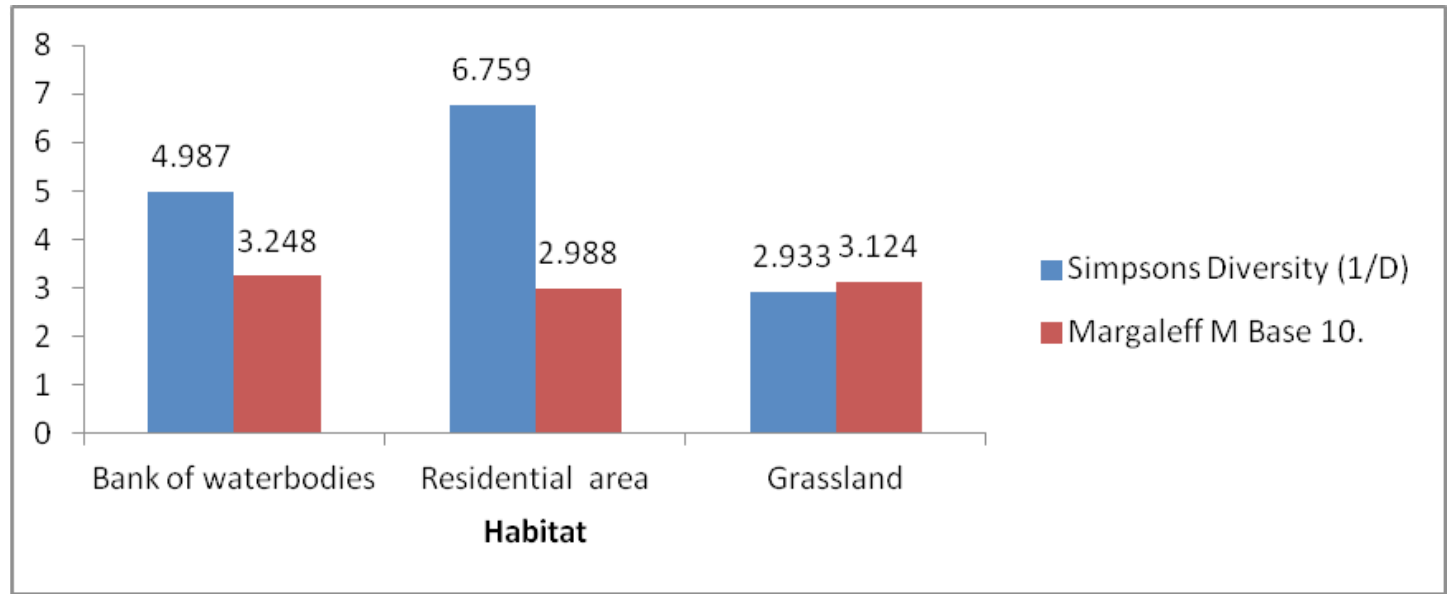

Figure 6. Simpsons Diversity Index (1/D) and Margaleff M Base 10 index in different habitats

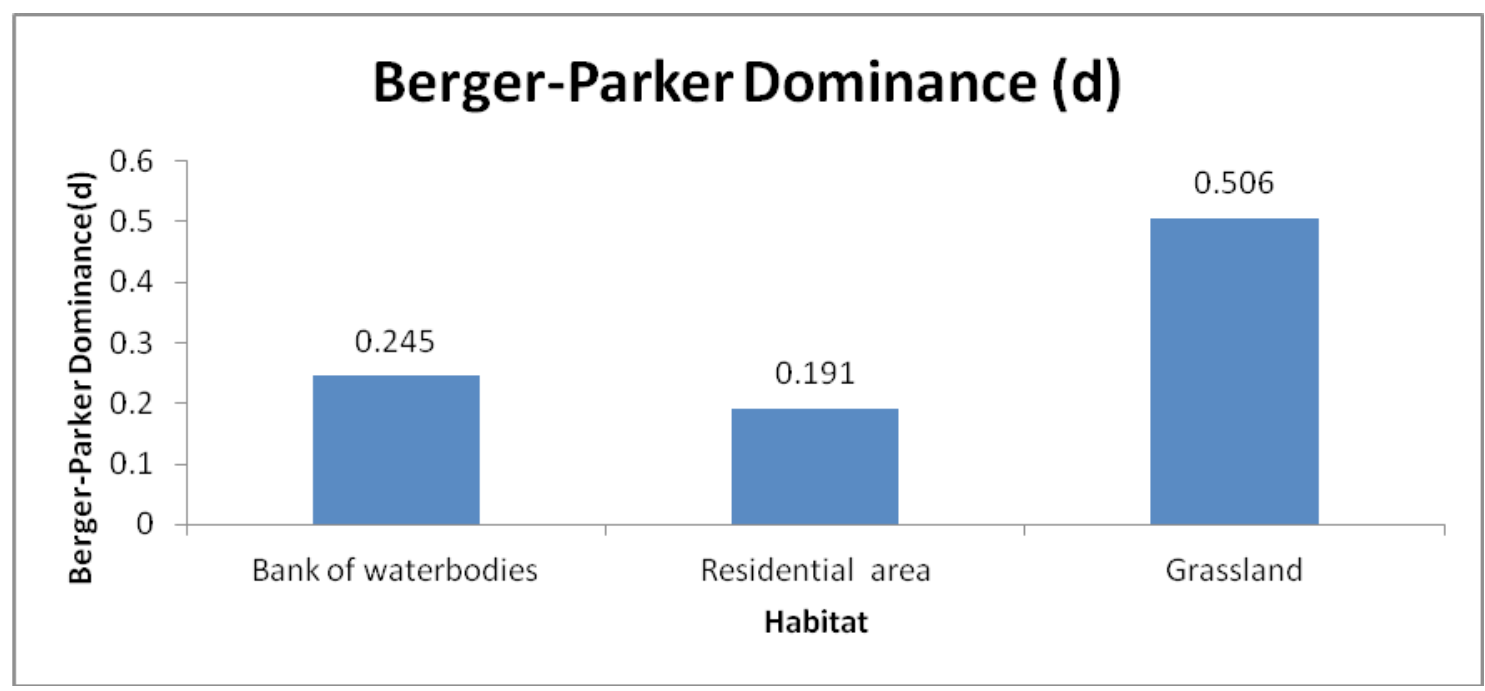

Figure 7. Berger- Parker Dominance $(d)$ in different habitats

\section{Results of Diversity}

Figure 4 reveals the number of earthworm species recorded in the different habitats during August 2016 July 2017. The highest number of species (7) was recorded in the residential areas, the least in grassland habitat (4).

The number of genera recorded was also highest in the residential areas (5), followed by bank of water bodies (3) and the lowest in grassland (2).

The Shannon-Wiener Diversity Index (Shannon H' Log Base 10) value was also the highest in the residential areas (0.832), followed by the bank of water bodies (0.692), while the lowest (0.527) was recorded in grassland habitat (Figure 5).

The highest Shannon-Wiener Evenness Index (Shannon J') value was found in the bank of water bodies
(0.99), followed by the residential areas (0.984) and the lowest (0.876) in grassland.

The highest Simpsons Diversity Index (1/D) value was also found in the residential areas (6.759), followed by the bank of water bodies (4.987), with the lowest (2.933) in grassland habitat (Figure 5).

The highest Margaleff M Base 10 index value was found in the bank of water bodies (3.248), followed by grassland habitat (3.124) and the lowest (2.988) in the residential areas.

The Berger-Parker Dominance (d) Index value was the highest in grassland (0.506), followed by the bank of water bodies $(0.245)$ while the lowest $(0.191)$ was recorded in the residential areas. 


\section{Cluster Analysis}

Bray-Curtis Cluster Analysis (Single Link)

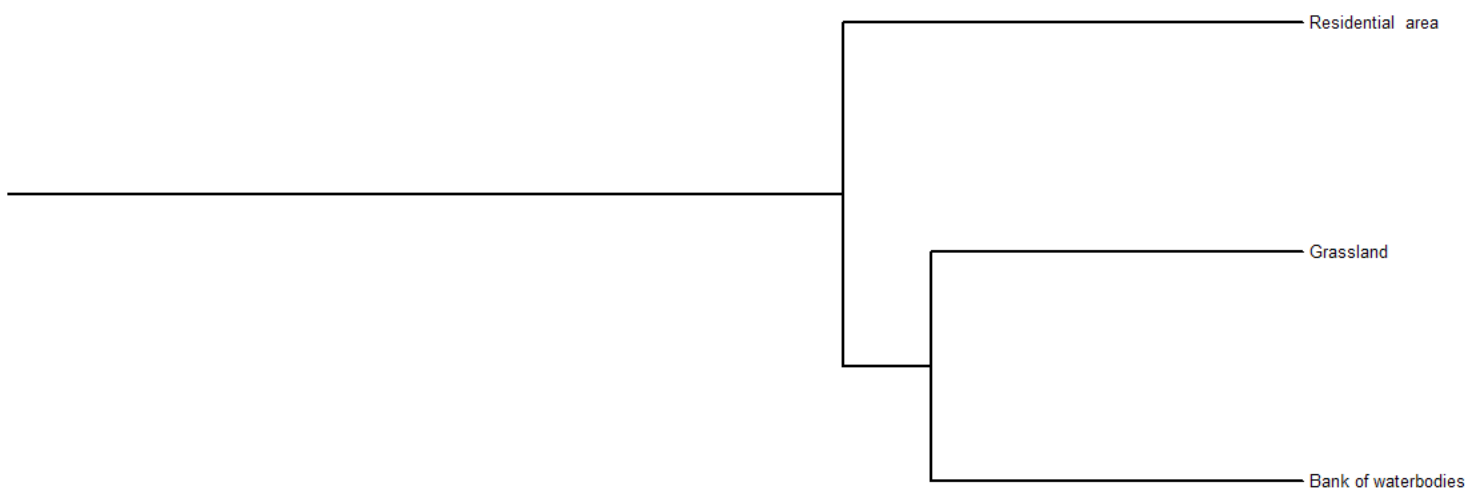

0. \% Similarity

100

\begin{tabular}{|l|c|c|c|}
\hline Similarity Matrix & & & \\
\hline Bank of water bodies & Residential area Grassland & & \\
\hline Bank of water bodies & $*$ & 62.259 & 71.2934 \\
\hline Residential area & $*$ & $*$ & 64.467 \\
\hline Grassland & $*$ & $*$ & $*$ \\
\hline
\end{tabular}

Figure 8. Cluster analysis of the three study sites based on data collected during August 2016- July 2017.

Results of cluster analysis of the three study sites based on data collected during August 2016- July 2017 are presented in Figure 8. The highest similarity was observed between bank of water bodies and grassland (71.29) habitats, and the lowest similarity was recorded between residential areas and bank of water bodies (62.25).

\section{Discussion}

Diversity and abundance of earthworms studied in three varied habitats in the field of SRFTI campus. The surveys were done from August 2016-July 201. The species richness, diversities, evenness and the dominance were analyzed using the following indices of Shannon-Wiener Diversity Index (Shannon H' Log Base 10), ShannonWiener Evenness Index (Shannon J'), Simpsons Diversity Index (1/D) and Berger-Parker Dominance (d) Index.

Present survey indicates the presence of eight species of earthworm. The highest abundance with highest diversity is found in residential areas, though the lowest abundance found in the bank of water bodies and lowest diversity found in the grassland habitat.

Ecologists call the number of species in an area is its richness. Species richness, i.e., the number of different species represented in the habitats is recorded maximum at the residential areas. Earthworm activity depends upon an adequate availability of soil moisture besides other factors (Edwards and Bohlen, 1996). Edwards and Bohlen (1996) stated that earthworm diversity ranged from 1 to 15 species, while most earthworm communities contained around 3-6 species. Similar observation found in SRFTI, the species richness of all the habitat types ranged from 4-7 species. Fragoso et al., (1999) suggest that the species number in a given earthworm community, which is the easiest measure of species diversity, ranging from 3-17 in tropical and temperate ecosystems. In this respect, habitats of SRFTI, with earthworm communities having $4-7$, exhibit the similar diversity. 
The Shannon-Wiener Diversity Index (Shannon H' Log Base 10) value and Simpsons Diversity Index (1/D) value depicts the highest in the residential areas with the lowest were recorded in grassland. On the contrary Margaleff $M$ Base 10 index shows the highest diversity values in the bank of the water bodies and lowest in residential areas. Thus the outcome from this index was considerably different from other index. Though the Shannon-Wiener Evenness Index (Shannon J') depicts the highest values in the bank of water bodies with lowest in grassland habitat. Thus, it is suggested that Shannon Index of diversity, Shannon Index of evenness and Simpson Index of diversity along with Berger-Parker Index of dominance properly reflected the diversity status than that by Margaleff Index. Lee, 1985 stated that earthworm diversity is greater in natural systems than the interfered habitat. Grassland habitat has constant disturbance due to children activities and gives the lowest diversity and evenness. The bank of water bodies have trees around and high moisture. Attained organic stability is due to leaf litter and constant moisture gave the highest evenness. Stable ecosystems have high species diversity than unstable environments (May, 1979). SRFTI has an undisturbed environment and thus gives 8 number of species altogether. Berger-Parker Dominance (d) index value exhibits the highest in grassland while the lowest were recorded in the bank of water bodies. This index is reciprocal form of diversity indices, so that an increase in diversity is the reduction in dominance (Hill, 1973).

Cluster analysis depicts the inter habitat percentage of similarity. The highest similarity was observed between bank of water bodies and grassland habitats.

\section{Conclusion}

Field observations suggested that the residential areas have different organic inputs, viz. inclusion of kitchen drainage and organic fertilizers of waste management enrich the soil layers with moderate moisture which releases from daily livelihood of human beings. Because of these factors, diversity and abundance was not depressed significantly during the dry season. Similar observation (Muldowney et al., 2003) that earthworms with more food availability give faster fecundity.

The bank of the water bodies are always moisture soil organic inputs, viz. inclusion of leaves, litter alter the soil environmental conditions that improve the moderate earthworm diversity in the campus. Erikson-Hamel and Whalen (2006) showed that increased soil moisture, temperature and microbial activity gives increased in growth of earthworms significantly.

The grassland is used mainly for children play ground. Seasonal flowers are planted by the authority, where cow dung is used for manuring. It is not at all grazing field of any animals. Earthworm communities are influenced by moisture and texture of the soil of flower garden. Since it has seasonal flowers, soils have more nutrients due to rotation of flower. Regular watering and organic amendments in the habitat to grow emerging flowers are one of the increasing factors of earthworm diversity. Though the lesser value recorded in the disturbed playground grass. Thus grassland habitat gave moderate abundance with lower diversity.

Due to high abundance of Metaphire peguana and Metaphire posthuma in all the habitats, the species may serve as potential indicator of important soil rehabilitation agent that affects various soil properties and plant growth.

The study revealed that the residential area is the best habitat for the highest diversity and abundance.

\section{Acknowledgement}

I would like to thank the Director, Satyajit Ray Film and Television Institute (SRFTI), Kolkata for providing me the permission and giving opportunity to work in the campus.

\section{References}

Anderson, M. and Ingram, J.S.I. 1993. Tropical soil biology and fertility: A handbook of Methods, 2nd ed. Edited by J. M. Anderson and J. S. I. Ingram. Wallingford, Oxford shire: CAB International; pp. 221.

Baskin, Y. 2005. Under Ground: how creatures of mud and dirt shape our world. Washington D.C.: Island Press.

Coleman, D.C., Crossley Jr., D.A. and Hendrix, P.F. 2004. Fundamentals of Soil Ecology, $2^{\text {nd }}$ ed. Elsevier Academic Press, USA.

Dash, M.C. and Patra, D.C. 1977. Density, biomass and energy budget of a tropical Earthworm population from a grassland site in Orissa, India. Rev. Ecol. Bioi. Soil, 16: 79-83.

Edwards, C.A. and Bohlen, P.J. 1996. Biology and ecology of earthworms. $3^{\text {rd }}$ ed. Chapman and Hall. London, UK. pp. 426. 
Eriksen-Hamel, N.S. and Whalen, J.K. 2006. Growth rates of Aporrectodea caliginosa (Oligochaeta: Lumbricidae) as influenced by soil temperature and moisture

Indisturbed and undisturbed soil columns. Pedobiologia, 50: 207-215.

Fragoso, C., and Lavelle, P. 1992. Earthworm communities of tropical rain forests. Soil Biol. Biochem, 24(12): 1397-1408.

Fragoso, C., Lavelle, P., Blanchart, E., Senapati, B.K., Jimenez, J.J., Martinez, M. Decaëns, T. and Tondoh, J. 1999. Earthworm communities of tropical Agroecosystems: origin, structure and influence of management practices. In: Lavelle P. Brussaard, L. Hendrix, P. ed. Earthworm

Management in tropical agroecosystems. Wallingford: CABI, p. 27-55.

Hill, M.O. 1973. Diversity and evenness: a unifying notation and its consequences. Ecology, 54: 427-432.

Lavelle, P., Douhalei, N. and Sow, B. 1974. Influence de Iahumidite du sol sur in Consummation ETI Acroissance de millsoniaanomaladansI Asavane Deslanto. Ann. Univ. J.Abidjan, 7: 305-314.

Lee, K.E. 1985. Earthworms: Their ecology and relationships with soils and land use. Academic Press. New York. pp. 1-420.

Ludwig, J.A. and Reynolds, J.F. 1988. Statistical ecology: A primer on methods and Computing. John Wiley \& Son, Inc., New York, pp. 337.

May, R.M. 1979. The structure and dynamics of ecological communities, In: Anderson, R.M., Turner, B.D., Taylar, L.R. eds. Population dynamics 20th symposium of British Ecological society Blackwell, Oxford. Pp. 385-407.

Muldowney, J., Curry, J.P., O'Keefe, J. and Schmidt, O. 2003. Relationships between Earthworm populations, grassland management and badger densities in county Kilkenny, Ireland. Pedobiologia, 47: 913-919.

Satchell, J.E. 1983. Earthworm microbiology, Ch.31 Earthworm Ecology from Darwin to Vermiculture. pp. 352 (ed.) Satchell JE, Chapman and Hall, London.

Sathianarayanan, A. and Khan, A.K. 2006. Diversity, distribution and abundance of earthworms

InPondicherry region. Tropical Ecology, 47(1): 139-144 